\title{
The uniqueness of values and personal traits of Generation $Z$ students in the innovative educational space of the southern region of Russia
}

\author{
Vlada Pishchik ${ }^{1, *}$ and Zoya Spivachuk $^{2}$ \\ ${ }^{1}$ Don State Technical University, 344003, Gagarin sq., 1, Rostov-on-don, Russia \\ ${ }^{2}$ Russian State University of Justice. Crimean branch, 295006, Pavlenko str., 5, Simferopol, Russia
}

\begin{abstract}
The value gap between the subjects of the educational space makes it difficult to introduce innovations in the process of interaction between a teacher and a student. The study is aimed at comparing the Big five (TIPI-RU) traits and Schwartz values in Generation $\mathrm{Z}$ students. Students $(N=396)$ are residents of the Crimea and the Rostov region. We assumed that if respondents belong to the same age group and are identified with the same Generation $Z$ group, they must have similar personality traits and value structure. As a result, we found out that the values of conservatism and self-transcendence prevailed in both groups. The Crimean students have the values of universalism, kindness, security is associated with achievements. The Rostov students have the most expressed values of universalism and independence, security is associated with power. The Crimean students were dominated by personal traits: conscientiousness, consent and openness to experience, extroversion. The Rostov students showed conscientiousness and openness to experience. We concluded that the differences between the two groups mainly relate to the value structure and the respondents' area of residence plays a role. The research can be useful for developing work and training programs for young people.
\end{abstract}

\section{Introduction}

\subsection{Relevance of the research}

In the XXI century one can witness a generational gap between the subjects of the educational space. In this regard, the introduction of innovations comes along with the psychological characteristics of generations. First of all, it is necessary to take into account the values of generations.

The value construct remains relevant in the research space. Culture opens up a palette of values of different groups of the population. Changing, culture corrects the values of

\footnotetext{
* Corresponding author: vladaph@yandex.ru
} 
generations [1-3]. Today we are faced with a young Generation Z. This generation is represented by those whose birth dates are 2000-2017. It is characterized by late adulthood, fascination with social networks, liberal views on drugs, free sex relations, religion, the predominance of unisex clothing, etc. $[4,5]$. The authors define generation as: "Generations describe a group of individuals born during contiguous birth years who experience similar cultural contexts. "These individuals both experience a shared historical and cultural environment and also shape culture in their own way" [5, p. 131]. A similar cultural context sets the values of a group of generations. Generational change involves changing the cultural context and changing the values of generations. The question of the speed and global impact of various significant historical events on the values of generations and generational identity remains open [5-6]. It is likely that generational differences will appear earlier in some regions.

The relevance of the topic determined the purpose of our study to compare the values of Generation Z in the southern region of Russia, Simferopol (Crimea) and Rostov-on-Don (Southern Federal District).

\subsection{Literature review}

We presented large-scale research of values [7-10], which are generalized in modern research [11-13]. Within the framework of the axiological approach, sociologists have determined that values are a transcendent, ideal being, they are significant, supra-historical. They are sought for, but not achieved. They are hierarchically arranged.

Values are defined as internalized cognitive structures that determine moral choices, priorities in life, and readiness to acquire meaning and see patterns [14]. We can conclude that any fact can be the value, the normative principle that has significance, values belong to the cognitive sphere and can be components of the orientation of the individual. Values are connected with emotions.

It is established that basic values to a large extent remain constant throughout a person's life [11-12]. Modern research shows turning points that lead to changes in the trends of values in world culture $[7,15]$. We can conclude that sociological research returned historicity and dynamism to values.

In the study Inglehart [15] emphasized 2 main parameters of values: traditional-rational, survival-self-expression. According to modern research [15] in the youth environment, the values of survival have replaced the values of self-expression, rational, but not in all cultures. Each culture sets its own boundaries and the main direction of values.

Schwartz identified the following values: independence, stimulation, hedonism, achievement, power, security, conformity, tradition, benevolence, and universalism [7]. He combined them in the following areas: Openness to change, Conservation, SelfEnhancement, and Self-Transcendence. In 2004, the author found out that in Africa and Western Europe, the value of hierarchy is higher; in Eastern Europe, conservatism, equality and intellectual autonomy are higher. In Africa, the skill is higher. Affective autonomy is higher in Western Europe.

Gradually, the constructs of Sh. Schwartz's values are modified. In the studies of Rudnev M., Magun V. [16] it is shown that in all countries the value axis "Conservatism Openness to change" and "Assertiveness - Concern" linked negatively, negatively correlated and values "Openness to change" values "Care" and "Conservatism" and "Assertiveness".

We can conclude that psychologists and sociologists brought the values of the individual and society closer to the motivation, the nuclear components of personality. Based on this, the authors built typologies and hierarchies of values. In fact, values 
determined the integrity of the individual and their consistency in society. The general methodological attitude of psychologists and sociologists led to this.

Generational values connect the values of society and the individual. The values of the generations were compared in various studies [3, 5, 17]. The problem of uniformity of values within a single generation remains. We have already compared groups within the same generation [17]. Now it is interesting to compare one generation group, but in different areas of the southern region of our country.

\section{Methodology}

\subsection{Objectives of the Study}

The sample of the empirical study consisted of the following groups: the Rostov group of university students of Rostov-on-Don, 196 people (total number is 300 persons), (100 girls, 96 boys); the Crimean group - students of Simferopol, 200 people (total number is 400 people), 2000-2001 years of birth (105 girls and 95 boys). All participants were identified with Generation Z.

Based on the presented problem, we put forward several research hypotheses: We assume that:

$\mathrm{H} 1$ : there are statistically significant differences in values depending on the generation group.

$\mathrm{H} 2$ : there are statistically significant differences in personality characteristics depending on the generation group.

H3: the structure of indicators of the two groups within a generation differs.

\subsection{Instruments}

To identify the traits of the generation, we used the method-Ten-item personality inventory (TIPI-RU) or Big fives [18]. The method includes 5 personality traits: extroversion, consent, conscientiousness, emotional stability, and openness to experience. In order to identify the value orientation of representatives of the generation, we used the Schwartz value measurement questionnaire [7]. The methodology measures 10 values: independence, stimulation, hedonism, achievement, power, security, conformity, tradition, benevolence, and universalism. To determine identification with the generation, the Twenge questionnaire was used [19]. The questionnaire includes 15 statements reflecting the main manifestations of Generation Z: self-presentation in networks, attitudes to religion, sex, alcohol, politics, drugs, relationships with parents, driving experience, ethnic tolerance, frequency of contact with peers, and feelings of loneliness.

The statistical software package SPSS version 21 was used for data processing. We also used the nonparametric Mann-Whitney U-criterion test and the exploratory factor analysis (principal components Method).

\section{Results}

The results of the value measurement method are presented in Table. 1.

In the group of the Rostov students, the most expressed values are kindness, universalism, independence, and security. In the group of the Crimean students, the most expressed values are: conformity, kindness, universalism, independence, and security. 
The significance of differences was found in both groups in the direction of conservatism and self-transcendence. The group of students from Simferopol showed more expressed values. The hypothesis $\mathrm{H} 1$ is proved.

Table 1. Descriptive statistics on values in groups

\begin{tabular}{|c|c|c|c|c|c|c|c|c|c|c|c|c|}
\hline \multirow[b]{2}{*}{ Indicators } & \multicolumn{2}{|c|}{$\mathbf{N}$} & \multicolumn{2}{|c|}{ Min } & \multicolumn{2}{|c|}{ Max } & \multicolumn{2}{|c|}{ M } & \multicolumn{2}{|c|}{ SD } & \multirow[t]{2}{*}{$\mathbf{U}$} & \multirow[t]{2}{*}{$\mathbf{P}$} \\
\hline & $\mathbf{R}$ & $\mathbf{S}$ & $\mathbf{R}$ & $\mathbf{S}$ & $\mathbf{R}$ & $\mathbf{S}$ & $\mathbf{R}$ & $\mathbf{S}$ & $\mathbf{R}$ & $\mathbf{S}$ & & \\
\hline \multicolumn{13}{|l|}{ Concervatism } \\
\hline Security & 196 & 200 & 6 & 17 & 27 & 33 & 20,63 & 25,63 & 5,11 & 4,16 & 376 & 0,002 \\
\hline Conformity & 196 & 200 & 4 & 9 & 21 & 26 & 12,68 & 20,63 & 5,21 & 4,28 & 427,5 & 0,00 \\
\hline Tradition & 196 & 200 & 3 & 8 & 23 & 31 & 11,72 & 19,45 & 5,50 & 6,30 & 403 & 0,00 \\
\hline \multicolumn{13}{|l|}{ Self-transcendence } \\
\hline Benevolence & 196 & 200 & 9 & 20 & 30 & 33 & 22,13 & 26,95 & 5,36 & 3,88 & 373 & 0,002 \\
\hline Universalism & 196 & 200 & 8 & 22 & 45 & 53 & 29,40 & 39,95 & 9,33 & 8,03 & 395 & 0,00 \\
\hline \multicolumn{13}{|l|}{ Openness to changes } \\
\hline Self-Direction & 196 & 200 & 16 & 17 & 29 & 34 & 23,59 & 24,72 & 3,81 & 5,11 & & \\
\hline Stimulation & 196 & 200 & 7 & 8 & 19 & 21 & 13,86 & 14,77 & 3,27 & 3,54 & & \\
\hline \multicolumn{13}{|l|}{ Self-exaltation } \\
\hline Hedonism & 196 & 200 & 6 & 9 & 20 & 21 & 13,86 & 15,40 & 3,65 & 3,64 & & \\
\hline Achievement & 196 & 200 & 10 & 13 & 25 & 26 & 19,27 & 19,72 & 3,79 & 3,96 & & \\
\hline \begin{tabular}{|l|} 
Power \\
\end{tabular} & 196 & 200 & 9 & 10 & 25 & 27 & 14,86 & 14,81 & 5,33 & 7,35 & & \\
\hline $\begin{array}{l}\mathrm{N} \text { valid (according to } \\
\text { the list) }\end{array}$ & 196 & 200 & & & & & & & & & & \\
\hline
\end{tabular}

$\mathrm{R}$ - Rostov-on-Don

$\mathrm{S}$ - Simferopol

Values are related to personal characteristics. The results are shown in Table 2.

Table 2. Descriptive statistics on personal characteristics in groups

\begin{tabular}{|c|c|c|c|c|c|c|c|c|c|c|c|c|}
\hline \multirow[b]{2}{*}{ Indicators } & \multicolumn{2}{|c|}{$\mathbf{N}$} & \multicolumn{2}{|c|}{ Min } & \multicolumn{2}{|c|}{ Max } & \multicolumn{2}{|c|}{ M } & \multicolumn{2}{|c|}{ SD } & \multirow{2}{*}{\multicolumn{2}{|c|}{\begin{tabular}{l|l}
$\mathbf{U}$ & $\mathbf{P}$ \\
$\mathbf{R}$ & $\mathbf{S}$
\end{tabular}}} \\
\hline & $\mathbf{R}$ & $\mathbf{S}$ & $\mathbf{R}$ & $\mathbf{S}$ & $\mathbf{R}$ & $\mathbf{S}$ & $\mathbf{R}$ & $\mathbf{S}$ & $\mathbf{R}$ & $\mathbf{S}$ & & \\
\hline Extraversion & 196 & 200 & 4 & 4 & 14 & 13 & 9,54 & 7,812 & 2,73 & 2,40 & 144 & 0,02 \\
\hline \begin{tabular}{|l|} 
Consent \\
\end{tabular} & 196 & 200 & 5 & 6 & 14 & 14 & 8,90 & 9,86 & 2,38 & 2,23 & & \\
\hline Conscientiousness & 196 & 200 & 6 & 8 & 14 & 15 & 11,54 & 11,31 & 2,10 & 1,78 & & \\
\hline Emotional stability & 196 & 200 & 3 & 4 & 13 & 12 & 8,36 & 8,22 & 3,51 & 1,63 & & \\
\hline $\begin{array}{l}\text { Openness to } \\
\text { experience }\end{array}$ & 196 & 200 & 8 & 3 & 14 & 14 & 10,77 & 9,63 & 2,06 & 2,47 & & \\
\hline $\begin{array}{l}\mathrm{N} \text { valid (according } \\
\text { to the list) }\end{array}$ & 196 & 200 & & & & & & & & & & \\
\hline
\end{tabular}

In both groups, the most pronounced personal qualities are conscientiousness and consent. In the group of Rostov students, openness to experience and extraversion are more pronounced.

The significance of differences was found only on the extroversion scale. Rostov students are more extroverted than Crimean students. The H2 hypothesis is partially proved.

Next, we conducted the factorization of the received data.

Factorization of the data showed that in the group of Rostov students, 4 factors were identified, constituting $87.3 \%$ of the variance (Table 3 ).

Table 3. Matrix of components in the group of the Rostov students 


\begin{tabular}{|l|r|r|r|r|}
\hline \multirow{2}{*}{ Variables } & \multicolumn{4}{|c|}{ Componts } \\
\cline { 2 - 5 } & $\mathbf{1}$ & $\mathbf{2}$ & $\mathbf{3}$ & $\mathbf{4}$ \\
\hline Conformity & 0,653 & 0,57 & $-0,21$ & $-0,115$ \\
\hline Achievements & 0,565 & $-0,423$ & $-0,291$ & 0,085 \\
\hline Openness to experience & 0,303 & $-0,641$ & $-0,127$ & 0,305 \\
\hline Emotional stability & $-0,192$ & 0,008 & 0,848 & 0,206 \\
\hline Conscientiousness & 0,249 & 0,352 & $-0,358$ & 0,514 \\
\hline Consent & 0,214 & 0,125 & 0,648 & 0,019 \\
\hline Extraversion & $-0,434$ & 0,365 & $-0,315$ & $-0,04$ \\
\hline Power & 0,779 & $-0,121$ & $-0,032$ & $-0,486$ \\
\hline Security & 0,723 & 0,192 & $-0,068$ & 0,074 \\
\hline Tradition & 0,136 & 0,596 & 0,036 & 0,454 \\
\hline Benevolence & 0,25 & 0,18 & 0,438 & $-0,221$ \\
\hline Hedonism & $-0,105$ & $-0,491$ & 0,127 & 0,661 \\
\hline Stimulation & 0,673 & $-0,545$ & 0,032 & $-0,032$ \\
\hline Self-direction & 0,555 & 0,065 & 0,347 & $-0,11$ \\
\hline Universalism & 0,679 & 0,316 & 0,111 & 0,434 \\
\hline
\end{tabular}

In the group of Rostov students: the 1 scomponent is represented by power (weight $=0.78)$, security $(0.72)$, universalism $(0.68)$, stimulation $(0.67)$, achievement $(0.56)$, self-direction $(0.55)$. The 2 nd component includes tradition $(0.59)$, conformity $(0.57)$. The 3 rd component included emotional stability (0.85), consent $(0.65)$. The 4th component included hedonism (0.67), conscientiousness (0.51).

In the group of the Crimean students, 5 factors were identified, amounting to $85.5 \%$ (Table 4).

Table 4. Matrix of components in the group of the Crimean students

\begin{tabular}{|c|c|c|c|c|c|}
\hline \multirow[b]{2}{*}{ Variables } & \multicolumn{5}{|c|}{ Components } \\
\hline & 1 & 2 & 3 & 4 & 5 \\
\hline Conformity & 0,41 & 0,371 & 0,519 & $-0,527$ & 0,117 \\
\hline Achievements & 0,816 & $-0,336$ & $-0,026$ & $-0,136$ & 0,358 \\
\hline Openness to experience & 0,224 & 0,565 & $-0,482$ & 0,121 & 0,511 \\
\hline Emotional stability & 0,122 & 0,067 & 0,694 & 0,2 & 0,149 \\
\hline Conscientiousness & 0,428 & $-0,475$ & 0,43 & 0,002 & $-0,059$ \\
\hline Consent & 0,268 & 0,226 & 0,749 & 0,3 & 0,034 \\
\hline Extraversion & 0,146 & $-0,362$ & 0,016 & 0,768 & 0,322 \\
\hline Power & 0,543 & $-0,677$ & $-0,104$ & $-0,247$ & 0,3 \\
\hline Security & 0,85 & 0,053 & $-0,141$ & 0,287 & $-0,186$ \\
\hline Tradition & 0,803 & 0,041 & $-0,028$ & $-0,38$ & 0,185 \\
\hline Benevolence & 0,774 & 0,148 & 0,225 & 0,078 & $-0,253$ \\
\hline Hedonism & 0,536 & $-0,531$ & $-0,266$ & 0,237 & $-0,195$ \\
\hline Stimulation & 0,704 & 0,496 & $-0,313$ & 0,01 & $-0,012$ \\
\hline Self-direction & 0,677 & $-0,126$ & $-0,203$ & $-0,1$ & $-0,458$ \\
\hline Universalism & 0,521 & 0,728 & $-0,056$ & 0,288 & $-0,073$ \\
\hline
\end{tabular}

In the group of the Crimean students, the 1 st component included the value of security (0.85), achievements $(0.82)$, traditions $(0.80)$, benevolence $(0.77)$, stimulation $(0.70)$, selfdirection (0.68), hedonism (0.54). The 2 nd component included power ( -0.68$)$, hedonism ($0.53)$. The 3 rd component include consent (0.75), emotional stability ( 0.69$)$, and conformity 
(0.52). The th4 component included extraversion (0.77) and conformity $(-0.53)$. The 5 th component was represented by openness to experience (0.51).

The Crimean students are more hedonistic than the Rostov students.

The H3 hypothesis has been proven.

\section{Discussion}

The purpose of our study was to compare groups belonging to the same Generation $\mathrm{Z}$ in various regions of the southern region of our country. We assumed that if respondents belong to the same age group and identify with the same generation group, then they must have similar personality traits and value structure. It turned out that the area of residence factor plays a significant role in the manifestation of indicators. Especially if we consider that the youth of Crimea experienced an important political event-the annexation of Crimea to Russia. And the youth of the Rostov region live in a politically more stable atmosphere.

As a result, conservatism and self-transcendence were most pronounced in the group of the Crimean students. For the Rostov students, the first factor was the value of power. These results are confirmed in studies $[7,17,20]$. The Crimean students strive for positive interaction. They are tolerant. They are more conformist and tend to maintain tradition. This is typical of collectivist cultures and people in crisis. The value of security was important for both groups of students, but with the predominance of the Crimean students. It can be explained by the current difficult situation in the world $[9,21]$.

It was found out that in both groups, the predominant personal quality conscientiousness. A conscientious person is one who has the traits of order and selfdiscipline among others; a pleasant person, good-natured, and treats people with respect and honor. This result is combined with the study [18].

In the groups, the predominant trait was openness to experience. A person who is open to experience is open to everything new, both in relationships and in ideas and new objects. The results are comparable with the studies [18, 22]. It was found out that openness decreases with age [23]. The Crimean students have higher extroversion, which can compensate hedonism. When extroversion is expressed, the person is assertive and active [24].

In the factor structure in the group of the Rostov students, power occupies an important place. In the group of the Crimean students, security occupies an important place. For the Rostov students, social status and dominance over others are important, while for the Crimean students, political stability and harmony in relations are more important. The results are comparable with the studies [25].

\section{Conclusion}

The research presented here is an important step in what appears to be a promising area of research into the relationship between the Big five traits and generational values. Differences between groups within the same Generation $\mathrm{Z}$ were obtained, but to a lesser extent. We can say that the generation group is predominantly homogeneous. While our findings have a number of important limitations, they represent progress toward a better understanding of how the Big five traits and values affect how people evaluate themselves and their lives. This may affect the likelihood that individuals with different personality traits and values will build their lives differently in different areas of the southern region of Russia.

Teachers working with students of Generation Z, should be aware that: all training topics should be associated with the development problems of the world; applicable 
material should be clearly structured; imaging is an important principle of educational materials presentation; presentation of applicability of acquired knowledge, the search for meaning; getting feedback through social networks; it is necessary to apply an individual approach, to emphasize the uniqueness of the student; the speed of perception of the material; agreements are significant as well as conventions in addressing educational problems and in supporting standards.

The author thanks the scientific supervisor of the project Postnikova M. I. for her help in collecting data for the research. This work was supported by the RFBR grant Project No. 18-013-00910 "Dynamics of generation values as a marker of transformation of social relations in the Russian society". For research articles with several authors, a short paragraph specifying their individual contributions must be provided. The following statements should be used "Conceptualization, V. P.; Methodology, Software, Validation, V. P.; Formal Analysis, Investigation, Resources, V. P., Z. S.; Data Curation, Writing-Original Draft Preparation, Writing-Review \& Editing, Visualization, Supervision, Project Administration, Funding Acquisition, V. P., Z. S.

\section{References}

1. S. L. Drob, An axiological model of the relationship between consciousness and value. New Ideas in Psychology, 43, 57-63 (2016) DOI: 10.1016/j.newideapsych.2016.02.002

2. P. B. Smith, Cultural Values Versus Cultural Norms as Predictors of Differences in Helping Behaviors and in Emotion Regulation: A Preliminary Nation-Level Test Related to the Leung-Morris Model, 13, 739-766 (2017) https://doi.org/10.1017/mor.2017.51

3. S. Beugelsdijk, C. Welzel, Dimensions and Dynamics of National Culture: Synthesizing Hofstede With Inglehart, Journal of Cross-Cultural Psychology, 49, 14691505 (2018) https://doi.org/10.1177/0022022118798505

4. P. J. Schenarts, Now Arriving: Surgical Trainees From Generation Z. Journal of Surgical Education, 77(2), 246-253 (2020) https://doi.org/10.1016/j.jsurg.2019.09.004

5. S. Campbell, J. M. Twenge, W. Keith, Campbel Fuzzy But Useful Constructs: Making Sense of the Differences Between Generations. Work, Aging and Retirement, 3(2), 130-139 (2017) doi:10.1093/workar/wax001

6. J. Marcus, S. Ceylan, C. Ergin, Not So «Traditional» Anymore? Generational Shifts on Schwartz Values in Turkey. Journal of Cross-Cultural Psychology, 48(1), 58-74 (2016) https://doi.org/10.1177/0022022116673909

7. S. Schwartz, In: Virgil Zeigler-Hill, Todd Shackelford (eds) Encyclopedia of Personality and Individual Differences. Springer, Cham (2019) https://doi.org/10.1007/978-3-319-28099-8_2327-1

8. Live cultural map over time 1981 to 2015, URL: https://www.youtube.com/watch?v=ABWYOcru7js; Cultural map - WVS wave 6 (2010-2014)

http://www.worldvaluessurvey.org/images/Culture_Map_2017_conclusive.png (Last accessed 12.06.2020)

9. R. Inglehart, Culture Shift in Advanced Industrial Society, Princeton University Press (2018) DOI: $10.2307 /$ j.ctv346rbz

10. G. Hofstede, Dimensionalizing Cultures: The Hofstede Model in Context. Online Readings in Psychology and Culture, 2 (2011) URL: http://scholarworks.gvsu.edu/orpc/vol2/iss1/8 (Last accessed 12.06.2020) DOI: 10.9707/2307-0919.1014 
11. J. Cieciuch, S. H. Schwartz, E. Davidov, Values, Social Psychology of. International Encyclopedia of the Social \& Behavioral Sciences (Second Edition) 41-46 (2015) https://doi.org/10.1016/B978-0-08-097086-8.25098-8

12. K. V. Vodenko, V. I. Rodionova, L. A. Shvachkina, M. M. Shubina, The value-based and cultural matrix as a component of the national model of social development, Advances in Intelligent Systems and Computing, 622, 415-421 (2018) DOI: 10.1007/978-3-319-75383-6_53

13. H. C. Triandis, M. Gelfand, Subjective Culture. Encyclopedia of Human Behavior (Second Edition), 544-550 (2012) https://doi.org/10.1016/B978-0-12-375000-6.003499

14. D. Oyserman, Values, Psychology of International Encyclopedia of the Social \& Behavioral Sciences (Second Edition), 36-40 (2015) DOI: 10.1016/B0-08-0430767/01735-6

15. R. Inglehart, Culture Shift in Advanced Industrial Society, Princeton University Press (2018) DOI: $10.2307 / \mathrm{j} . \operatorname{ctv} 346 \mathrm{rbz}$

16. M. Rudnev, V. Magun, S. Schwartz, Relations Among Higher Order Values Around the World. Journal of Cross-Cultural Psychology, 49(8), 1165-1182 (2018) DOI $10.1177 / 0022022118782644$

17. V. Pishchik, A. Belousova, L. Ryumshina, The relationship of generations representatives in the educational environment. EDULEARN18 Proceedings 10th International Conference on Education and New Learning Technologies. 2-4 July, 1782-1786, Palma, Spain (2018) doi: 10.21125/edulearn.2018.0524

18. The SAGE encyclopedia of lifespan human development. Edited by: Marc H. Bornstein. SAGE Publications, Inc. (2018) DOI:http://dx.doi.org/10.4135/9781506307633

19. J. M. Twenge, iGen: Why today's super-connected kids are growing up less rebellious, more tolerant, less happy- and completely unprepared for adulthood and what that means for the rest of us (New York, NY, Atria Books 2017)

20. N. Lebedeva, S. Schwartz, F. J.R. Van De Vijver, J. Plucker, E. Bushina Domains of Everyday Creativity and Personal Values. Front. Psychol. 9, 2681 (2019) doi: 10.3389/fpsyg.2018.02681

21. V. Kotlyarova, A. Rudenko, P. Ponomarev, Traditional values as a national security factor in the age of globalization. Central Asia and the Caucasus, 18(2), 87-95 (2017)

22. N. A. Dmitrienko, S. I. Ershova, N. V. Serbinovskaya, E. L. Kutsova, E. N. Yurina, Self-Organizing Students Viability in Cultural Education Environment of Technical University. Indian journal of science and technology, 9(10) (2016) DOI:10.17485/IJST/2016/V9I16/91511

23. R. Lehmann, J. J.A. Denissen, M. Allemand, L. Penke, Age and gender differences in motivational manifestations of the Big Five from age 16 to 60. Developmental Psychology, 49(2), 365-383 (2013). https://doi.org/10.1037/a0028277

24. A. W. Lukaszewski, Extraversion. In: Zeigler-Hill V., Shackelford T. (eds) Encyclopedia of Personality and Individual Differences. Springer, Cham. (2016) https://doi.org/10.1007/978-3-319-28099-8_1071-1

25. I. Abakumova, A. Berberyan, H. Berberyan, Psychological characteristics of the value orientation system of Armenians in title ethnos and Russian diaspora. International Journal of Cognitive Research in Science, Engineering and Education, 7(2), 11-17 (2019) https://doi.org/10.5937/IJCRSEE1902011A 